\section{BENEFITS OF SUTURELESS AORTIC VALVES MAY NOT BE LIMITED TO REDUCED CROSSCLAMP TIME}

\section{To the Editor:}

I read the recent letter by Tavlasoglu and colleagues ${ }^{1}$ with great interest. The benefits of minimally invasive surgery for conventional aortic valve replacement performed through a partial upper sternotomy or right minithoracotomy have been reported to include not only reduced ventilation time, decreased incisional pain, reduced wound infections, reduced blood loss and transfusions, and decreased time to discharge but also significantly reduced mortality. ${ }^{2}$ Sutureless bioprostheses simplify aortic valve replacement, allowing more surgeons to perform minimally invasive aortic valve replacement with all its previously stated advantages. This innovation will also reduce crossclamp and cardiopulmonary bypass times, which may decrease morbidity and mortality. Salis and coworkers ${ }^{3}$ found that reducing bypass time by 30 minutes significantly decreased blood transfusions, neurologic complications, and infections, as well as reducing renal and multiorgan failure. These benefits are due to minimizing the time-dependent inflammatory response and also to reducing the number of gaseous or particulate microemboli. Maleszka and assoicates ${ }^{4}$ demonstrated that cardiopulmonary bypass time was an independent predictor for early

\footnotetext{
The Editor welcomes submissions for possible publication in the Letters to the Editor section that consist of commentary on an article published in the Journal or other relevant issues. Authors should: - Include no more than 500 words of text, three authors, and five references. - Type with double-spacing. - See http://jtcs.ctsnetjournals.org/misc/ifora.shtml for detailed submission instructions. - Submit the letter electronically via jtcvs.editorialmanager.com. Letters commenting on an article published in the JTCVS will be considered if they are received within 6 weeks of the time the article was published. Authors of the article being commented on will be given an opportunity of offer a timely response ( 2 weeks) to the letter. Authors of letters will be notified that the letter has been received. Unpublished letters cannot be returned.
}

mortality in elderly patients undergoing complex procedures.

Minh and colleagues ${ }^{5}$ investigated the use of sutureless bioprostheses in elderly patients to reduce mortality and morbidity associated with complex procedures. Sutureless bioprostheses reduce the crossclamp and cardiopulmonary bypass times, which is important not only because of the concern for myocardial protection during cardiac arrest, which is mandatory, but to reduce overall morbidity and mortality.

Transcatheter valve implantation permits the treatment of high-risk patients with aortic valve stenosis and degenerative aortic or mitral bioprostheses as well as patients who are not candidates for operation. For high-risk elderly patients who have multiple-valve disease and who are not currently considered candidates for transcatheter valve implantation, alternative procedures need to be evaluated to improve their quality of life with low operative morbidity and mortality.

Not only did the patient cohort of Minh and colleagues ${ }^{5}$ contain patients undergoing double-valve surgery, but also $60 \%$ of their patients underwent additional cardiac procedures. For these patients, the use of the sutureless valve resulted in a reduction in cardiopulmonary bypass time, which positively influenced their outcomes. To date, several thousand sutureless bioprostheses have been successfully implanted, with a maximum followup of 7 years. The comment by Tavlasoglu and colleagues ${ }^{1}$ that long-term data are needed is justified; however, available studies, including randomized trials, are promising and show excellent midterm results.

In their letter, Tavlasoglu and colleagues $^{1}$ also suggested that a force of 3 to 4 atmospheres on the stent and surrounding tissue could be the reason that 2 patients in the cohort of Minh and colleagues ${ }^{5}$ required the implantation of a permanent pacemaker. In the patient cohort of Minh and colleagues, ${ }^{5}$ which included patients undergoing septal myectomy, triplevalve surgery, and the maze procedure, Tavlasoglu and colleagues ${ }^{1}$ did not clearly identify which patients needed pacemakers. For transcatheter valve implantation, the forces at the native annulus are doubled or tripled during valvuloplasty or valve deployment, and not all of the annuli are heavily calcified. Many such patients also require a pacemaker insertion.

I believe that the message from Minh and colleagues' study ${ }^{5}$ in their original article is that sutureless bioprostheses should not only be considered in minimally invasive aortic valve replacement but also for patients undergoing complex surgical procedures, where their use could positively influence operative morbidity and mortality. Future studies are needed to identify patient cohorts who will benefit most from sutureless valves and determine which patients should undergo conventional aortic valve replacement.

Pascal M. Dohmen, MD, PhD

Department of Cardiovascular Surgery

Charité Hospital

Medical University Berlin

Berlin, Germany

\section{References}

1. Tavlasoglu M, Guler A, Yesil FG. Should sutureless aortic valve replacement be preferred only for decreasing aortic crossclamp time? J Thorac Cardiovasc Surg. 2014;147:1726-7.

2. Borger MA, Dohmen PM, Misfeld M, Mohr FW Current trends in aortic valve replacement development of the rapid deployment aortic valve replacement with the EDWARDS INTUITY valve system. Expert Rev Med Devices. 2013;10:461-70.

3. Salis S, Mazzanti VV, Merli G, Salvi L, Tedesco CC, Veglia F, et al. Cardiopulmonary bypass duration is an independent predictor of morbidity and mortality after cardiac surgery. J Cardiothorac Vasc Anesth. 2008;22:814-22.

4. Maleszka A, Kleikamp G, Zittermann A Serrano MR, Koerfer R. Simultaneous aortic and mitral valve replacement in octogenarians: a viable option? Ann Thorac Surg. 2008;86:1804-8.

5. Minh TH, Mazine A, Bouhout I, El-Hamamsy I, Carrier M, Bouchard D, et al. Expanding the indication for sutureless aortic valve replacement to patients with mitral disease. J Thorac Cardiovasc Surg. 2014;148:1354-9.

http://dx.doi.org/10.1016/ j.jtcvs.2014.09.032 